\title{
Computation of time energy gain in D-3He mixture: Energy deposited through deuterium ignition beam
}

\section{S. N. Hosseinimotlagh}

Department of Physics, Colleges of Sciences, Islamic Azad University of Shiraz, Iran

\begin{abstract}
The fast ignition approach to ICF consists in first compressing the fuel to high density by a suitable driver and then creating the hot spot required for ignition by means of a second external pulse. If the ignition beam is composed of deuterons, an additional energy is delivered to the target with increased energy gain. Therefore ,in this innovative suggestion, we consider deuterium beams for fast ignition in $\mathrm{D}+{ }^{3}$ Hemixture and solve the dynamical balance equations under the available physical conditions by considering a new average reactivity formula , then we compute the energy gain in this mixture .Our computational results show that we can get energy gain value larger than 4 at resonant temperature $(200 \mathrm{keV})$ of D+3 Hemixture. We select D+3 Hefuel, because $\mathrm{D}+{ }^{3}$ Hereaction is very attractive from a theoretical point of view since it does not produced neutrons. The $\mathrm{D}+{ }^{3}$ Hebenefits include full-lifetime materials, reduced radiation damage, less activation, absence of tritium breeding blankets ,highly efficient direct energy conversion, easier maintenance, proliferation resistance.
\end{abstract}

Key words: Fast Ignition, Deuteron Beam, Energy, Dynamics
This article is is licensed under a Creative Commons AttributionNonCommercial 4.0 International License.

Attribution-NonCommercial (CC BY-NC) license lets others remix, tweak, and build upon work non-commercially, and although the new works must also acknowledge \& be noncommercial.

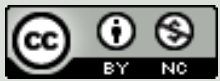

\author{
How to Cite: \\ Hosseinimotlagh SN. 2014. \\ Computation of time energy gain \\ in D-3He mixture: Energy \\ deposited through deuterium \\ ignition beam Asia Pacific Journal \\ of Energy and Environment, 1, 156- \\ 171.
}

Source of Support: Nil

Conflict of Interest: Non declared

\section{INTRODUCTION}

There is no doubt that one of the most difficult problems that a peaceful world will face in the 21th century will be to secure an adequate ,safe, clean and economical source of energy. One of the source of energy is nuclear fusion. Fusion energy which is the energy source that powers the stars, has its origin in nuclear fusion reactions. Inertial confinement fusion (ICF) is the major alternative to magnetic confined fusion. The indirect and direct drive approaches to ICF have been reviewed respectively byLindl et al.(1995 and 2004)[1] and Bodner (1998)[2]. Both rely on implosion of a spherical shell of deuterium tritium ice with a central core of $\mathrm{D}+\mathrm{T}$ gas to compress and ignite the fuel at a central hot 
spot. Fast ignition (FI) is a newer approach to ICF proposed in outline by Basov et al (1992)[3] and in much fuller detail by Tabak et al. (1994)[4]. Fuel compression and ignition are separated in FI by using a shell of fuel at solid density which is compressed by long pulse beams, together with short duration localized heating and ignition of the compressed fuel by a short pulse laser beam , as illustrated schematically in Figure1.

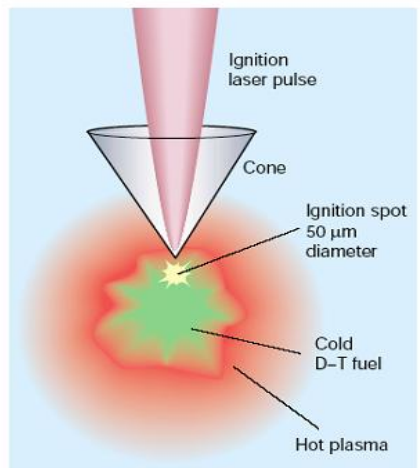

Figure 1. The fast ignition concept using implosion of a spherical shell with an inserted hollow cone to provide a path for the ignition laser pulse to generate electrons close to the compressed D+T plasma

The original concept of Tabak et al. assumed the short pulse laser beam would penetrate close to the dense fuel through a laser formed channel in the plasma and that laser generated relativistic electrons would ignite the fuel. Over the past year, there have been several observations of multi-MeV ion beams generated by high-intensity ultra-short laser pulses in the interaction with solid targets [5, 7-9]. Light ions, similar to electrons, can be generated due to laser-plasma interaction in a target, while a heavy ion beam must be produced by an external driver and transported to the target. In summary ,the fast ignition (FI) mechanism [4], in which a pellet containing the thermonuclear fuel is first compressed by a nanosecond laser pulse, and then irradiated by an intense "ignition" beam, initiated by a high power picosecond laser pulse, is one of the promising approaches to the realization of the inertial confinement fusion (ICF). The ignition beam could consist of laser-accelerated electrons, protons, heavier ions, or could consist of the laser beam itself. It had been predicted that the FI mechanism would require much smaller overall laser energies to achieve ignition than the more conventional central hot spot approach, and that it could deliver a much higher fusion gain, due to peculiarities of the pressure and density distributions during the ignition. It is clear, however, that interactions of electrons and ions with plasma, and most importantly the energy deposition mechanisms are essentially different. If the ignition beam is composed of deuterons, an additional energy is delivered to the target and increase target energy gain. Therefore, in thepresent studyas a particularly innovative,due to different advantages of $\mathrm{D}+{ }^{3} \mathrm{He}$ as already mentioned, we choose the $\mathrm{D}+{ }^{3} \mathrm{He}$ fuel with an deuteron ignition beam , under optimum conditions we compute the total energy deposited in the target and dynamically we determine energy gain. We must notice that $\mathrm{D}+{ }^{3}$ Hehas different advantages: they include fulllifetime materials, reduced radiation damage, less activation ,absence of tritium breeding blankets ,highly efficient direct energy conversion ,easier maintenance, proliferation resistance .In this direction,the physics of fusion reactions are described in detail in section II. Investigations of total deposited energy due to deuteron beam fast ignition in target fuel are described in section III. Balance equations of deuterium-helium3 mixture and interpretation of 
numerical obtained results are given in section IV. Finally, from the nature of this theoretical wر اينجا اعداد سكثنهار را به شكل رومى نوشتيم اما سا

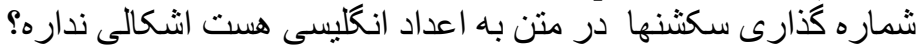

در كل متن بعضى جاها كه قبلا تصحيح كرده بوديد سايز و نوع فونتش با بقيه فرق داشت كه من همه ديه را درست كردم و منثل بقيه منت كردم.

\section{Physics of Fusion Reactions}

The main fusion reactions are:
$D+T \rightarrow{ }_{2}^{4} \mathrm{He}(3.5 \mathrm{MeV})+n(14.1 \mathrm{MeV})$
$D+{ }_{2}^{3} \mathrm{He} \rightarrow{ }_{2}^{4} \mathrm{He}(3.6 \mathrm{MeV})+p(14.7 \mathrm{MeV})$
$D+D \rightarrow{ }_{2}^{3} \mathrm{He}(0.82 \mathrm{MeV})+n(2.45 \mathrm{MeV})$
$\% 50$
$D+D \rightarrow T(1.01 \mathrm{MeV})+p(3.03 \mathrm{MeV})$
$\% 50 \quad(c-2)$

$\mathrm{D}+{ }^{3} \mathrm{He}$ reaction is very attractive from a theoretical point of view since it does not produced neutrons. A $\mathrm{D}+{ }^{3} \mathrm{He}$ fueled fusion reactor would also possess substantial safety and environmental advantages over $\mathrm{D}+\mathrm{T}$. Efficient $\mathrm{D}+{ }^{3} \mathrm{He}$ fusion energy would be beneficial to terrestrialelectricity ,space power, and space propulsion. Fusion using $\mathrm{D}+{ }^{3} \mathrm{He}$ fuel requires significant physics development particularly of plasma confinement in high performance alternate fusion concept. Economically accessible ${ }^{3} \mathrm{He}$ on earth exists in sufficient quantities (a few hundred $\mathrm{kg}$, equivalent to few thousand MW-years of fusion power ) for an engineering test. In a $\mathrm{D}+\mathrm{T}$ and $\mathrm{D}+3 \mathrm{He}$ fuel mixture $\mathrm{D}+\mathrm{D}$ reaction fusion also occurs. The main difficulties for $\mathrm{D}+{ }^{3} \mathrm{He}$ reaction are the high temperature conditions and the scarceness of ${ }^{3} \mathrm{He}$ on earth. The formula of fusion cross section for all these fusion reactions is given by [10] :

$$
\begin{aligned}
\sigma\left(E_{\text {lab }}\right)=-1638 & { }_{3}\left(1+\frac{m_{a}}{m_{b}}\right)^{2} \\
& \times\left[m _ { a } E _ { l a b } [ \operatorname { E x p } ( 3 1 . 4 0 Z _ { 1 } Z _ { 2 } \sqrt { \frac { m _ { a } } { E _ { l a b } } } ) - 1 ] \left\{\left(C_{1}+C_{2} E_{l a b}\right)^{2}\right.\right. \\
& \left.\left.+\left(C_{3}-\frac{2 \pi}{\left[\operatorname{Exp}\left(31.40 Z_{1} Z_{2} \sqrt{m_{a} / E_{l a b}}\right)-1\right]}\right)^{2}\right\}\right]^{-1}
\end{aligned}
$$

with 3 adjustable parameters $\left(C_{1}, C_{2}\right.$ and $C_{3}$ ) only. In equation (1), $m_{a}$ and $m_{b}$ are the mass number for the incident and target nucleus, respectively (e.g. $m_{a}=2$ for incident deuteron); $E_{\text {lab }}$ (deuteron energy in lab system )is in units of $\mathrm{keV}$ and $\sigma$ is in units of barn. The numerical values of $C_{1}, C_{2}$ and $C_{3}$ for these reactions are listed in Table.1 [10] .

Table 1. Numerical values of $C_{1}, C_{2}$ and $C_{3}$ for reactions $\mathrm{D}+\mathrm{T}, \mathrm{D}+{ }^{3} \mathrm{He}$ and $\mathrm{D}+\mathrm{D}$

\begin{tabular}{|c|c|c|c|}
\hline & $\mathrm{D}+\mathrm{T}$ & $\mathrm{D}+{ }^{3} \mathrm{He}$ & $\mathrm{D}+\mathrm{D}$ \\
\hline$C_{1}$ & -0.5405 & -1.1334 & -60.2641 \\
\hline$C_{2}$ & 0.005546 & 0.003039 & 0.05066 \\
\hline$C_{3}$ & -0.3909 & -0.6702 & -54.9932 \\
\hline
\end{tabular}

From this formula , a schematic diagram of the variations of fusion cross sections for these reactions in terms of $E_{l a b}$ are shown in Figure.2. Also by comparing our calculated numerical values with available experimental results as are shown in [10],we conclude that this formula is exact. 


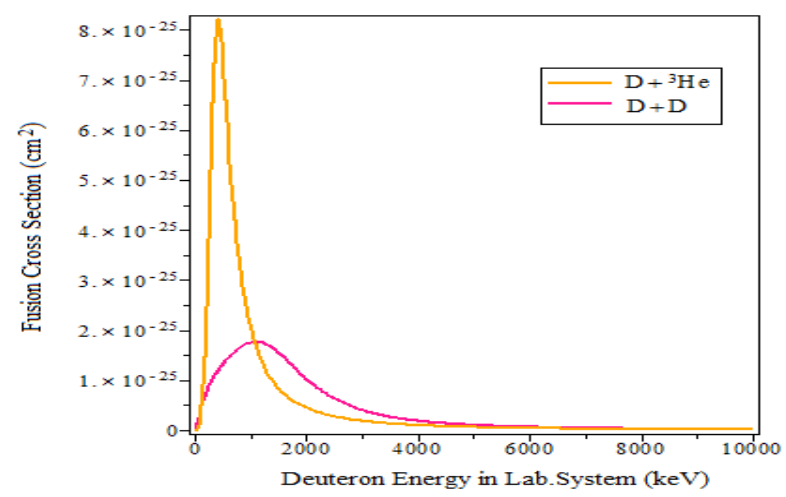

Figure.2.Variations of fusion cross sections versus Deuteron Energy in Lab System (keV) for different fusion reactions of $\mathrm{D}+{ }^{3} \mathrm{He}$ and $\mathrm{D}+\mathrm{D}$.

Another important quantity is the reactivity, defined as the probability of reaction per unit time per unit density of target nuclei. In the present simple case, it is just given by the product $\langle\sigma v\rangle$. We have [26]:

$$
<\sigma v>=\frac{4 \pi}{\left(2 \pi m_{r}\right)^{\frac{1}{2}}\left(k_{B} T\right)^{\frac{3}{2}}} \int_{0}^{\infty} \sigma(\varepsilon) \varepsilon \exp \left(-\frac{\varepsilon}{k_{B} T}\right) d \varepsilon
$$

Where $m_{r}$ is the reduced mass, $k_{B}$ is Boltzmann constant , $T$ is the temperature and $\varepsilon$ is energyin the center of mass frame. Note that $E_{l a b}=\frac{m_{a}+m_{b}}{m_{b}} \varepsilon د$

Using data in Table. 1 and inserting equation (1) into equation(2)and integrate on it for $\mathrm{D}+{ }^{3} \mathrm{He}$ and $\mathrm{D}+\mathrm{D}$ targets,Figure 3 presents plots of averaged reactivity for $\mathrm{D}+{ }^{3} \mathrm{He}$ and D+D.By way of comparison Figs. 2 with 3 we concluded that the cross section and averaged reactivity of $\mathrm{D}+{ }^{3} \mathrm{He}$ fusion reaction is greater thanD+D reaction, and $<$ $\sigma v>D+3 H e$ and $\angle \sigma v>D+D$ are strongly temperature dependent. However, for $\mathrm{D}+\mathrm{D}$ reaction $\langle\sigma v\rangle_{D+D}$ isminimized. Notice, however, that the resonance temperature, is the temperature where the probability for occurring fusion is maximized. In this manner, from Figs 3 , it will therefore be recognize that resonant temperature for both $\mathrm{D}+{ }^{3} \mathrm{He}$ and $\mathrm{D}+\mathrm{D}$ fusion reactions are approximately 200 and $300 \mathrm{keV}$,respectively.

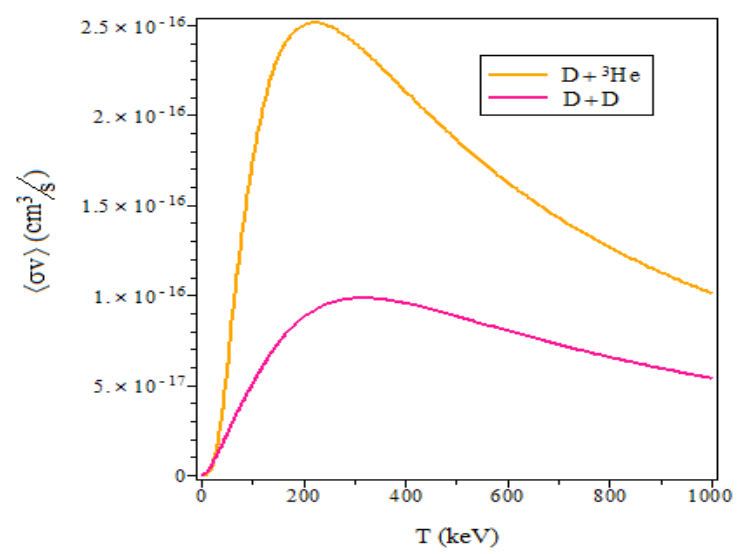

Figure 3:Variations of the averaged reactivity in terms of temperature for $\langle\sigma v\rangle_{D+}{ }^{3} \mathrm{He}$ and $<\sigma v>_{D+D}$ 


\section{TOTAL DEPOSITED ENERGY DUE TO DEUTERON BEAM FAST IGNITION IN TARGET FUEL}

Deuterons have been considered for fast ignition as well [11-16] .Bychenkov et al., considered an accelerated deuteron beam, but decided that deuterons would have too high an energy (7-8 MeV) to form the desired hot spot [11] .However, the recent proton acceleration experiments [17] suggest that the laser and converter foil parameters can be adjusted to achieve ion beams within the desired range of initial energies and spectra with low $\frac{\Delta E}{E}$ for maximum use of the beam. This reopens the door to a consideration of deuteron driven FI. Deuterons would not only provide proven ballistic focusing, but also fuse with the target fuel (both $\mathrm{D}$ and ${ }^{3} \mathrm{He}$ ) as they slow down [18] , providing a "bonus" energy gain. Depending on the target plasma conditions, this added fusion gain can provide a significant contribution[19]. We must notice that the idea of a bonusenergy for first time is presented by Xiaoling Yang and et.al at low temperatures [20].In this work we elaborate onthis idea, to compute the added energy released as the energetic deuterons interact with the target fuel ions of $\mathrm{D}+{ }^{3} \mathrm{He}$ in range of temperatures including resonant ones $(200 \mathrm{keV})$. This added energy increasesthe total energy gain.We use a modified energy multiplication factor $\varphi$ to estimate the bonus energy in terms of the added "hot spot" heating by beam-target fusion reaction for $\mathrm{D}+{ }^{3} \mathrm{He}$ [18] . The deuteron beam energy deposition range and time are also calculated for this reaction. The $\mathrm{F}$ value is the ratio between the fusion energy $E_{f}$ produced and the ion energy input $E_{I}$ to the plasma and for $\mathrm{D}+{ }^{3} \mathrm{He}$ reaction is given by [18] :

$F_{D+{ }^{3} \mathrm{He}}=n^{3} \mathrm{He} \frac{\int_{E_{t h}}^{E_{I}} S(E) d E}{E_{I}}$

where $E_{I}$ and $E_{t h}$ are, respectively, the average initial energy and the asymptotic thermalized energy of the injected single ion for this reactions.[18,21,22] .So ,we consider

$S(E) \equiv \sum_{k} K_{k}\left[<\sigma v(E)>_{b}\right]_{I k}\left(E_{f}\right)_{I k} /\left(\frac{d E}{d t}\right)$

where:

$\frac{1}{n^{3} H e}\left(\frac{d E}{d t}\right)=-\frac{Z_{I}^{2} e^{4} m_{e}^{1 / 2} E \ln \Lambda_{D+{ }^{3} H e}}{3 \pi(2 \pi)^{1 / 2} \varepsilon_{0}^{2} m_{I}\left(k T_{e}\right)^{3 / 2}}\left[1+\frac{3 \sqrt{\pi} m_{I}^{3 / 2}\left(k T_{e}\right)^{3 / 2}}{4 m_{k} m_{e}^{1 / 2} E^{3 / 2}}\right]$

where $m_{e}$ is the mass of electron and $m_{I}$ is the mass of the injected ion, both of which are in atomic mass unit (amu). $\langle\sigma V\rangle_{I k}$ is the fusion reactivity for the injected ion $I$ of species $k$ having atomic fraction $K_{k}$ in the target, $\left(E_{f}\right)_{I k}$ is the corresponding energy released per fusion, and $T_{e}$ is the target electron temperature [22] .By inserting Eq.(5) inside Eq.(3) we can see that the $n^{3} \mathrm{He}$ in Eq. (5) cancel that in Eq.(3), thus $F_{D+{ }^{3} H e}$ is nearly independent of the target density $\left(n_{{ }_{3} H e}\right) \cdot \ln \Lambda_{D+}{ }^{3} H e$ is the Coulomb logarithm for $\mathrm{D}+{ }^{3} \mathrm{He}$ reaction.

In the $\mathrm{D}+{ }^{3} \mathrm{He}$ fusion reaction the products are all energetic charged particles (14.7 MeV proton and 3.6 MeV alpha) based on the binary collision model, the Coulomb logarithm based slowing down process in the background plasma is usually defined as [23]:

$\ln \Lambda_{D+{ }^{3} H e}=14.8-\ln \left(\sqrt{n_{e}} / T_{e}\right)$

In Fig.4, the two and three dimensional variations of $\ln \Lambda_{D+}{ }^{3} \mathrm{He}$ are plotted. From this, we then clearly see thatln $\Lambda_{D+}{ }^{3} \mathrm{He}$ has a larger value at lower $T_{e}(\mathrm{keV})$ and highern ${ }_{e}\left(\mathrm{~cm}^{-3}\right)$. 

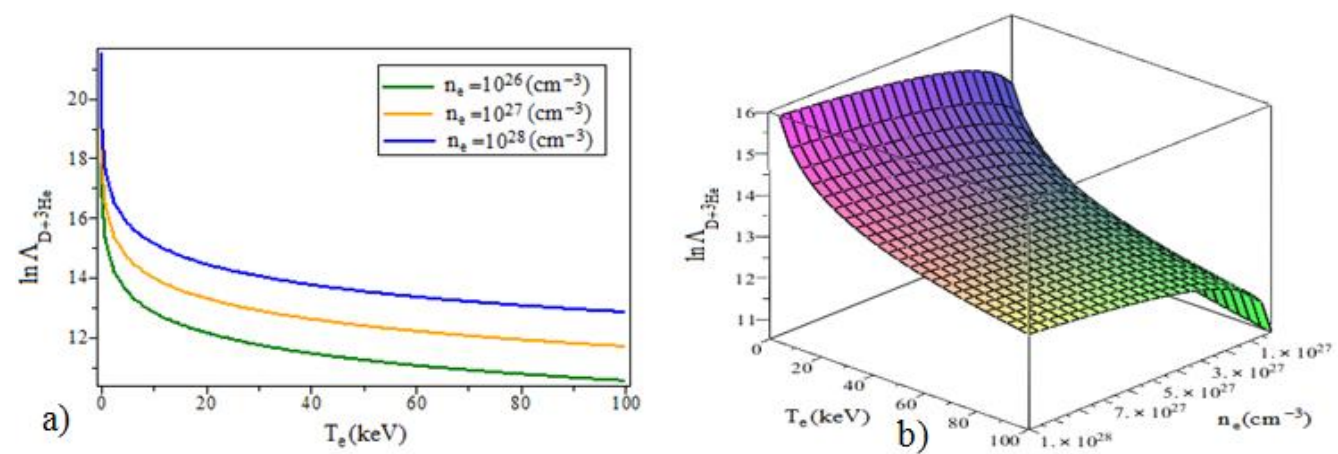

Figure 4: a)The two and b) three dimensional variations of $\ln \Lambda_{D+}{ }^{3} H e$ in terms of target density and temperature .

The $\left(E_{f}\right)_{I k}$ in Eq. (4) gives the energy released in the fusion reaction carried by the produced particles. For, $\mathrm{D}+{ }^{3} \mathrm{He}$ reaction in the target (see reaction (b)) only $20 \%$ of the fusion energy carried by the alphas is applicable for heating while for the D+D reaction about $63 \%$ of the total isapplicable (see reaction c) [20]. Therefore, to prevent confusion, we introduce a new factor $\varphi$ to represent the energy multiplication factor for the hot spot heating by the charged particles for $\mathrm{D}+{ }^{3} \mathrm{He}$ fusion reaction. We have $\varphi_{D+}{ }^{3} \mathrm{He}=$ $20 \% F_{D+}{ }^{3} \mathrm{He}$ and for D+D fusion in D+3 He mixture $\varphi_{D+D}=63 \% F_{D+}{ }^{3} \mathrm{He}$. In summary, the total energy that could be deposited into the target due to combined deuteron ion heating and beam-target fusion for $\mathrm{D}+{ }^{3} \mathrm{He}$ and $\mathrm{D}+\mathrm{D}$, respectively becomes:

$$
\varepsilon_{D+D}=E_{I}\left(1+\varphi_{D+D}\right)^{\varepsilon_{D+}{ }^{3} \mathrm{He}}=E_{I}\left(1+\varphi_{D+{ }^{3} \mathrm{He}}\right)
$$

so it is seen that $\varphi$ plays the role of a "bonus energy" for deuteron driven fast ignition. To avoid confusion, please note that the $\varepsilon$ here is the total energy deposited by the ion beam plus any contribution from its beam-target fusion in the hot spot, but not the total input energy to the target which is often cited in energy studies and represents the total laser compression plus fast ignition energy delivered to the total target, also the deuteron stopping range and stopping time can be calculated by following equations [20]:

$R_{S}=\int_{E_{t h}}^{E_{I}} v_{D} d E /\left(\frac{d E}{d t}\right)$

$t_{S}=\int_{E_{t h}}^{E_{I}} d E /\left(\frac{d E}{d t}\right)$

Where, $\left(\frac{d E}{d t}\right)$ are calculated from Eqs.(5) for $\mathrm{D}+{ }^{3} \mathrm{He}$ reactions, the deuteron velocity is $v_{D}=\sqrt{\frac{2 E}{m_{D}}}$.For calculating the total energy deposited into the target of $\mathrm{D}+{ }^{3} \mathrm{He}$ mixture at first step we substitute equation (6) into equation (5),then at second step the obtained result is replaced into equation.(4) and at third step the result of second step is inserted into equation (3) and we compute, $F_{D+}{ }^{3} \mathrm{He}$ and $F_{D+D}$ in $\mathrm{D}+{ }^{3} \mathrm{He}$ reaction at step 4 we use these parameters for determining of $\varphi_{D+D}$ and $\varphi_{D+}{ }^{3}{ }_{e}$. Finally, results are delivered by the last step inserted inEq.(7) and thus we have the numerical values of $\varepsilon_{D+}{ }^{3} \mathrm{He}, \varepsilon_{D+D}$ in $\mathrm{D}+{ }^{3} \mathrm{He}$ for $10^{26} \leq$ $n_{e}\left(\mathrm{~cm}^{-3}\right) \leq 10^{28}[25], 0 \leq T_{e}(\mathrm{keV}) \leq 200$ and deuteron energy $\mathrm{E}$, with range of $0 \leq$ $E(\mathrm{MeV}) \leq 10$. Also under these conditions we can calculate the deuteron stopping range and stopping time by using equations(8) and (9)for $\mathrm{D}+3 \mathrm{He}$ mixture .These parameters are denoted 
respectively by, $t_{S_{D+}{ }^{3} \mathrm{He}}, R_{S_{D+}{ }^{3} \mathrm{He}}$. The given numerical results are given in Figs.5 to 12 . Figure.5 show the results of our calculations of $\varphi_{D+}{ }^{3} \mathrm{He}, \varphi_{D+D} \quad, \varepsilon_{D+}{ }^{3} \mathrm{He}$ and $\varepsilon_{D+D} \quad$ in the case of $n_{e}=10^{26}\left(\mathrm{~cm}^{-3}\right)$. Please note that in order to have a better comparisonof the numerical values of $\varphi_{D+}{ }^{3} \mathrm{He}, \varphi_{D+D} \quad \varepsilon_{D+}{ }^{3} \mathrm{He}$ and $\varepsilon_{D+D}$ in each cases and stressing out theirchanges with temperature and electron densitywe show their maximum values in Table.2. From Figure.5 we see that multiplication factors $\varphi_{D+D}, \varphi_{D+}{ }^{3} \mathrm{He}$ increase by increasing temperature from 1 to $200 \mathrm{keV}$ (resonance temperature of $\mathrm{D}+{ }^{3} \mathrm{He}$ ) The value of total energy deposited in hot spot $\left(\varepsilon_{D+}{ }^{3} \mathrm{He}\right.$ and $\left.\varepsilon_{D+D}\right)$ by increasing temperature from 1 to $200 \mathrm{keV}$ increases(see Table.2). Also , the value of total energy deposited by increasing deuteron energy in range of 0 to $10000 \mathrm{keV}$ increases(see Figure.5). By increasing electron density from $n_{e}=10^{26}$ to $10^{28}\left(\mathrm{~cm}^{-3}\right)$ the amount of total deposited energy of $\varepsilon_{D+}{ }^{3} \mathrm{He}$ and $\varepsilon_{D+D}$ and also the amount of multiplication factors $\varphi_{D+}{ }^{3} \mathrm{He}$ and $\varphi_{D+D}$ are decreased(see Table.2). Comparing numerical values of multiplication factors $\varphi_{D+D}$ and $\varphi_{D+{ }^{3} H e}$ we can say that $\varphi_{D+D}$ is higher than $\varphi_{D+}{ }^{3} H e$ .Therefore the total energy deposited $\varepsilon_{D+D}$ is higher than $\varepsilon_{D+{ }^{3} H e}$ (see Table.2). From Figure.6,we see clearly that the stopping time remarkablyincreases by increasing temperature from $1 \mathrm{keV}$ to $200 \mathrm{keV}$, also $t_{S_{D+}{ }^{3} \mathrm{He}}$ increases by increasing deuteron energy. We must notice that the values of $t_{S_{D+}{ }^{3} \mathrm{He}}$ is reduced by increasing electron density, $n_{e}$,from $10^{26}$ to $10^{28}\left(\mathrm{~cm}^{-3}\right)$.In the $3 \mathrm{D}$ pictures, the temperature-dependence of $t_{S_{D+}{ }^{3} \mathrm{He}}$ is manifest. Numerical results of $t_{S_{D+}{ }^{3} \mathrm{He}}$ show that stopping time increases with temperature. The effect of helium-3 density $\left(n_{3} \mathrm{He}\right)$ from $10^{22}$ to $10^{24}\left(\mathrm{~cm}^{-3}\right)$ is important on the value of $t_{S_{D+}{ }^{3} \mathrm{He}}$ and in this range this quantity is reduced (by factor $\mathrm{O}(10)$ to $\mathrm{O}(100)$. In Figs.7-9 show that stopping range $\left(R_{S_{D+}{ }^{3} \mathrm{He}}\right)$ strongly increases with temperature from 1 to $200 \mathrm{keVand}$ also deuteron energy is an effective parameter on the stopping power such that by increasing this energy $R_{S_{D+}{ }^{3} \mathrm{He}}$ is increased. But the numerical values of $R_{S_{D+}{ }^{3} \mathrm{He}}$ are decreased by increasing electron density $n_{e}$ from $10^{26}$ to $10^{28} \mathrm{~cm}^{-3}$. The other parameter affects the numerical values of $R_{S_{D+}{ }^{3} \mathrm{He}}$ is target density $(\rho)$. If $\rho$ changes from 0.5 to $2.5\left(\mathrm{mg} / \mathrm{cm}^{3}\right)$ [27], stopping range is increased. Also , the other effective parameter decreasing stopping range is, $n^{3} \mathrm{He}$. Our calculation shows that by changing $n^{3} \mathrm{He}$ from $10^{22}$ to $10^{24} \mathrm{~cm}^{-3}, R_{S_{D+}{ }^{3} \mathrm{He}}$ is decreased by one or two orders of magnitude.
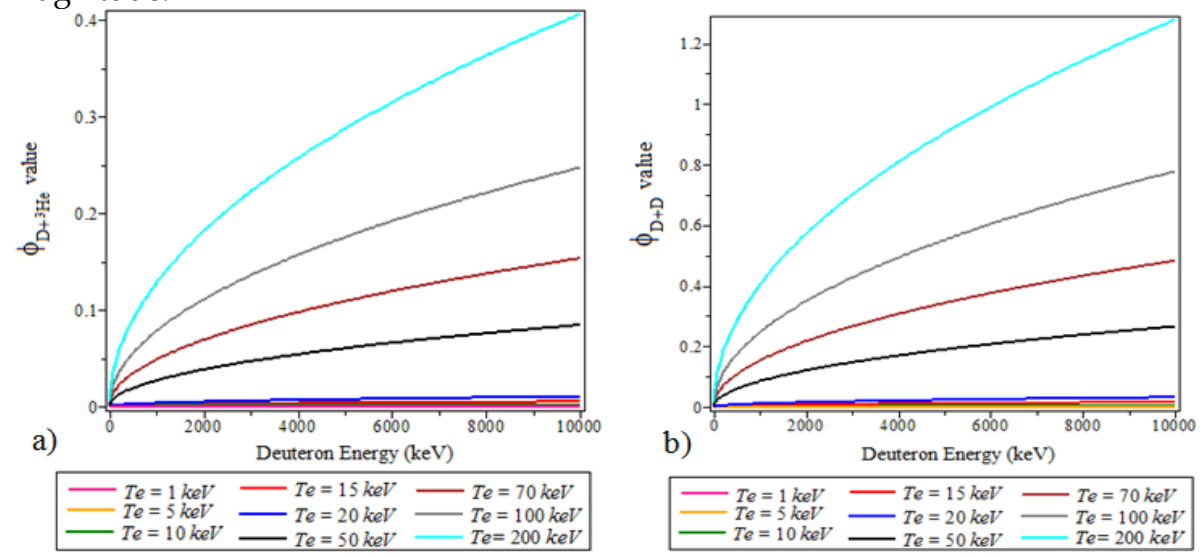
Asia Pacific Journal of Energy and Environment, Volume 1, No 2 (2014)

c)
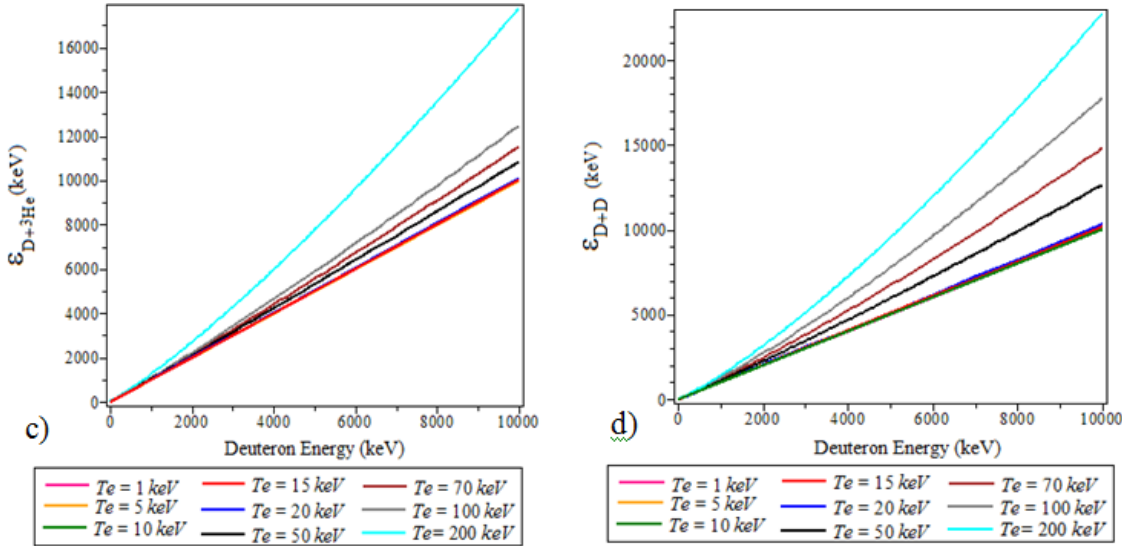

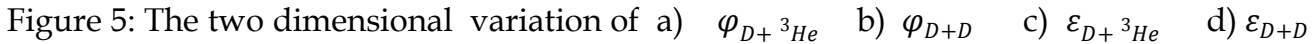
in terms of deuteron energy at different temperature in $\mathrm{D}+{ }^{3} \mathrm{He}$ mixture for $n_{e}=10^{26} \mathrm{~cm}^{-3}$.
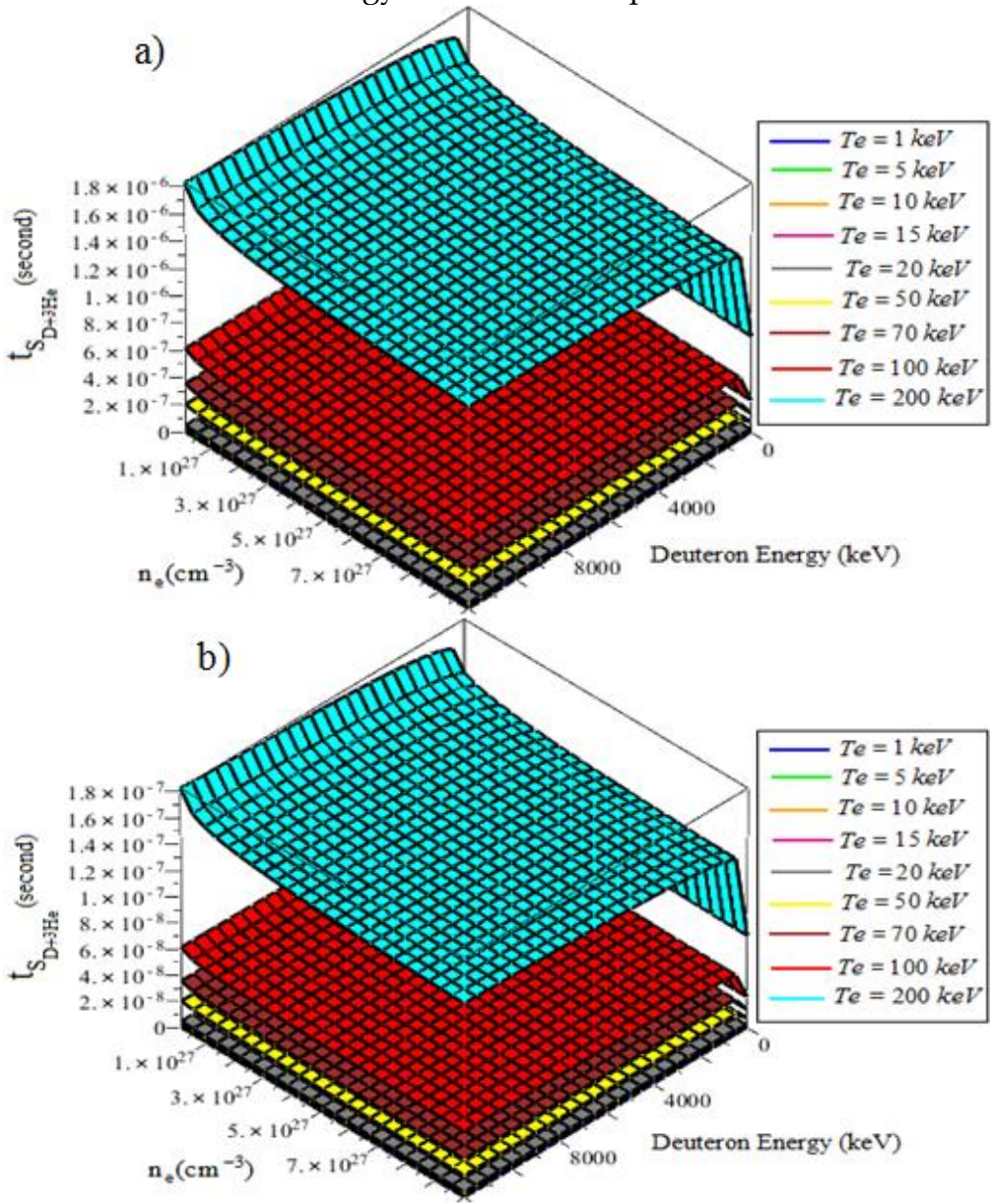


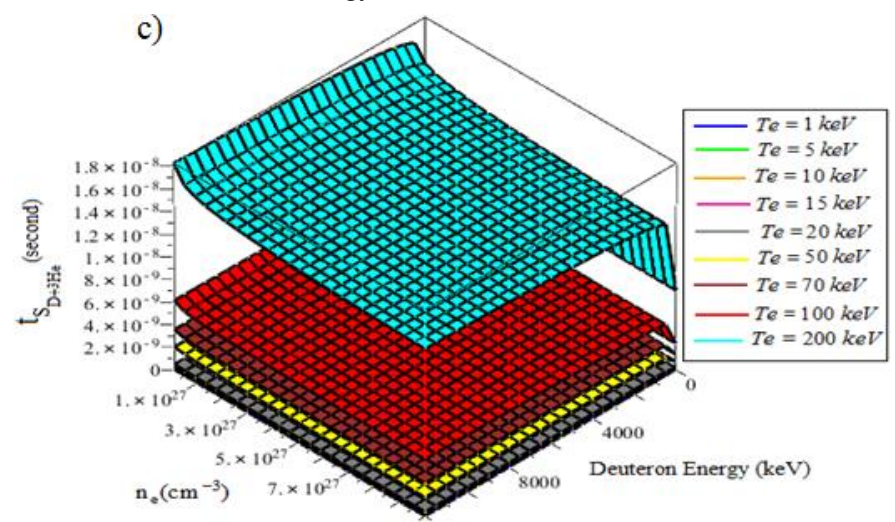

Figure 6: Three dimensional variations of stopping time versus electron density and deuteron energy at different temperatures in different density of ${ }^{3} \mathrm{He}$ a) $n^{3} \mathrm{He}=$ $10^{22}\left(\mathrm{~cm}^{-3}\right)$ b) $n^{{ }^{3} \mathrm{He}}=10^{23}\left(\mathrm{~cm}^{-3}\right)$ c) $n^{{ }^{3} \mathrm{He}}=10^{24}\left(\mathrm{~cm}^{-3}\right)$.

a) $\rho=0.5\left(\mathrm{mg} / \mathrm{cm}^{3}\right) \operatorname{andn}_{{ }_{\mathrm{He}}}=10^{22}\left(\mathrm{~cm}^{-3}\right)$

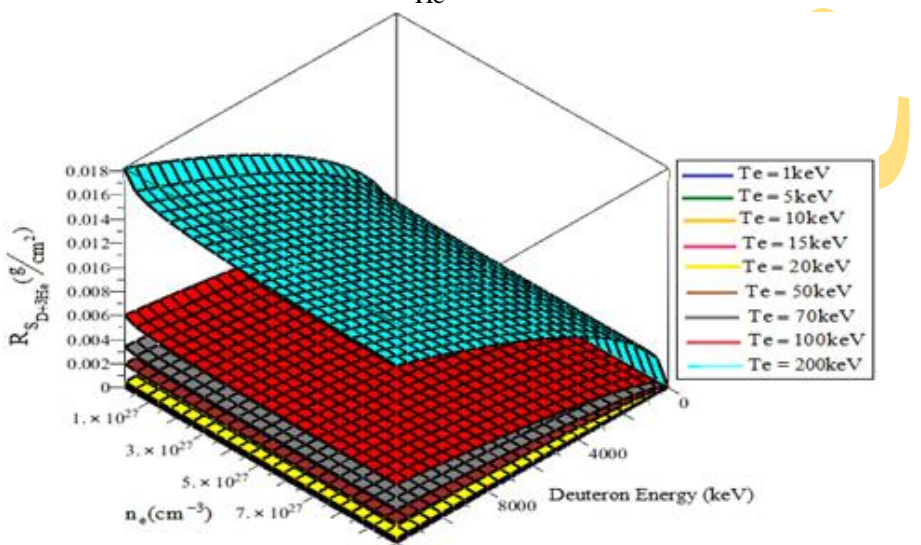

b) $\rho=1\left(\mathrm{mg} / \mathrm{cm}^{3}\right) \operatorname{andn}_{{ }_{3} \mathrm{He}}=10^{22}\left(\mathrm{~cm}^{-3}\right)$

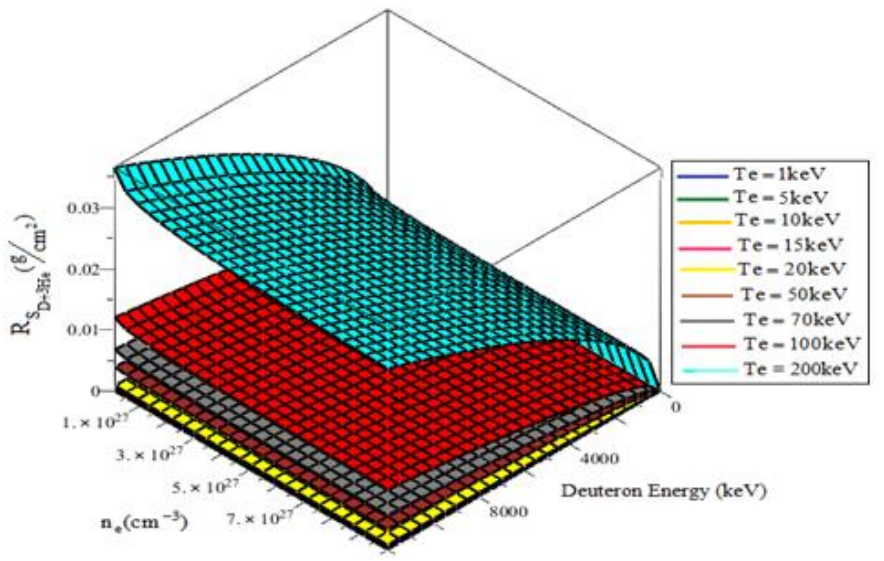


c) $\rho=2.5\left(\mathrm{mg} / \mathrm{cm}^{3}\right) \operatorname{andn}_{3_{\mathrm{He}}}=10^{22}\left(\mathrm{~cm}^{-3}\right)$

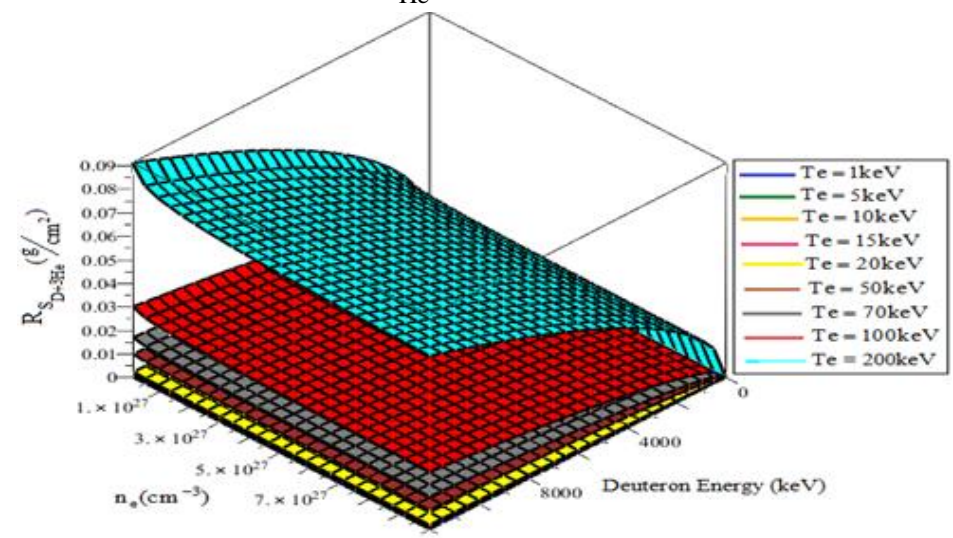

Figure7: The three dimensional variations of stopping range versus electron density and deuteron energy at different temperatures for three cases a) ,b) and c) in $\mathrm{D}+{ }^{3} \mathrm{He}$ mixture.

a) $\rho=0.5\left(\mathrm{mg} / \mathrm{cm}^{3}\right)$ and $\mathrm{n}_{3 \mathrm{He}}=10^{23}\left(\mathrm{~cm}^{-3}\right)$

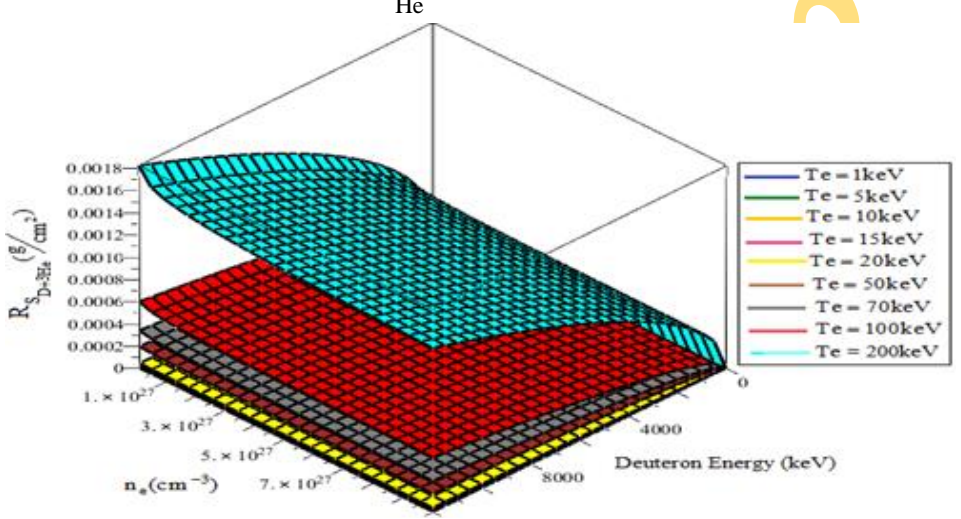

b) $\rho=1\left(\mathrm{mg} / \mathrm{cm}^{3}\right)$ and ${ }_{3}=10^{23}\left(\mathrm{~cm}^{-3}\right)$

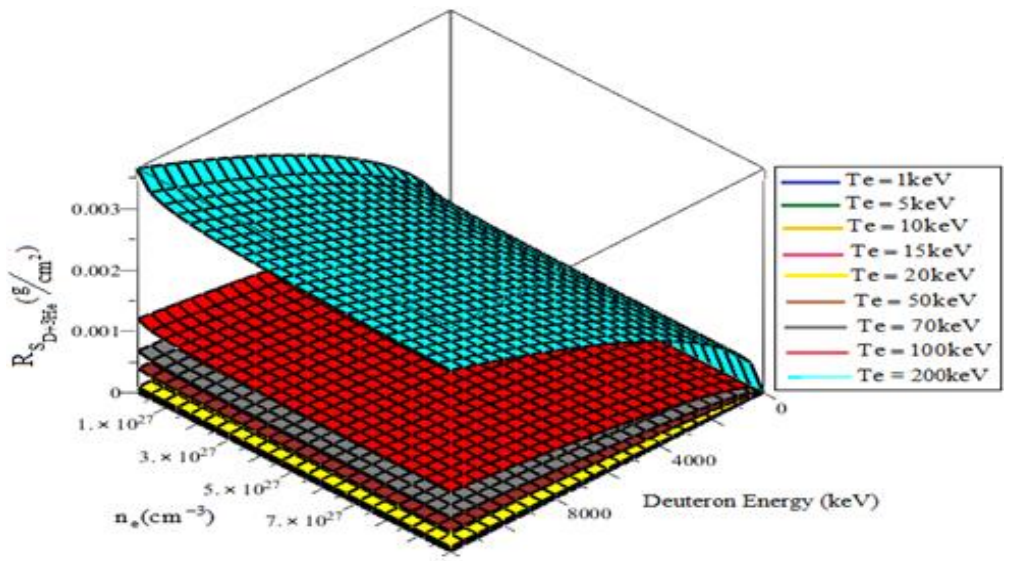


c) $\rho=2.5\left(\mathrm{mg} / \mathrm{cm}^{3}\right)$ and $\mathrm{n}_{3 \mathrm{He}}=10^{23}\left(\mathrm{~cm}^{-3}\right)$

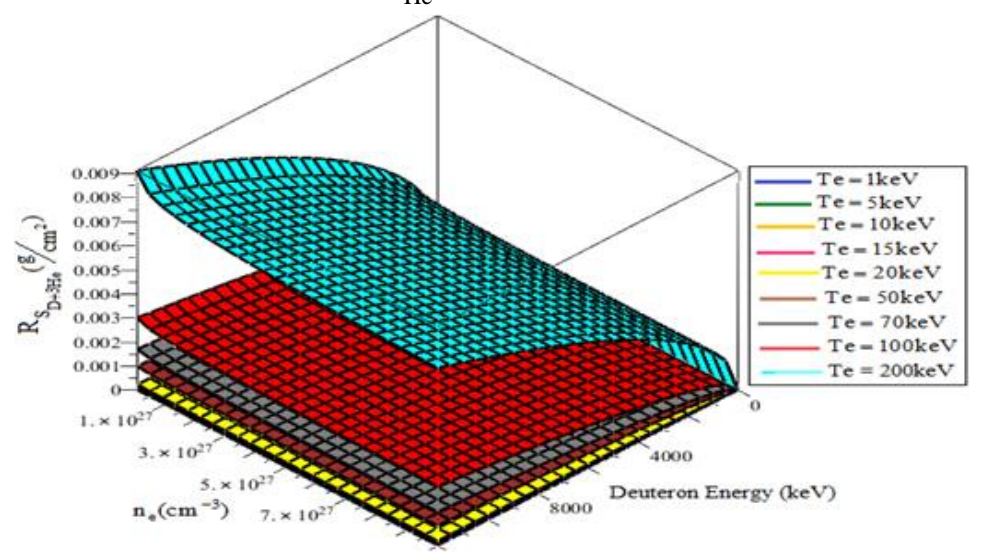

Figure 8: The three dimensional variations of stopping range versus electron density and deuteron energy at different temperatures for three cases a) ,b) and c) in $\mathrm{D}+{ }^{3} \mathrm{He}$ mixture.

a) $\rho=0.5\left(\mathrm{mg} / \mathrm{cm}^{3}\right)$ and $\mathrm{n}_{3 \mathrm{He}}=10^{24}\left(\mathrm{~cm}^{-3}\right)$

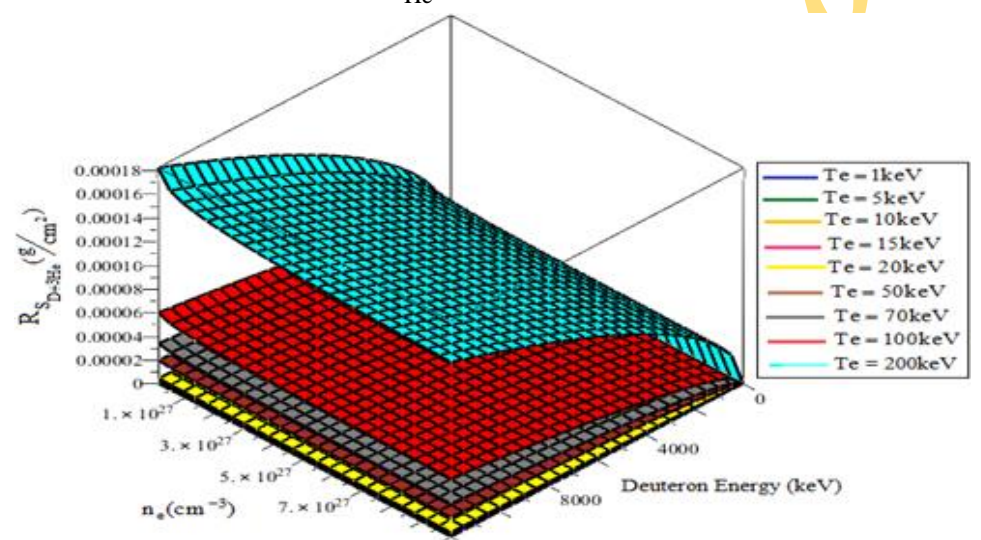

b) $\rho=1\left(\mathrm{mg} / \mathrm{cm}^{3}\right)$ and ${ }_{3 \mathrm{He}}=10^{24}\left(\mathrm{~cm}^{-3}\right)$

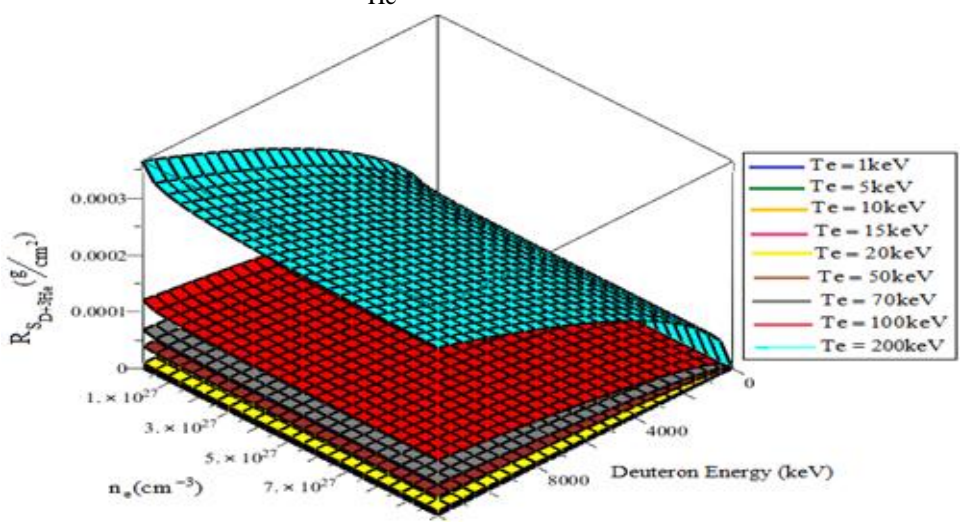




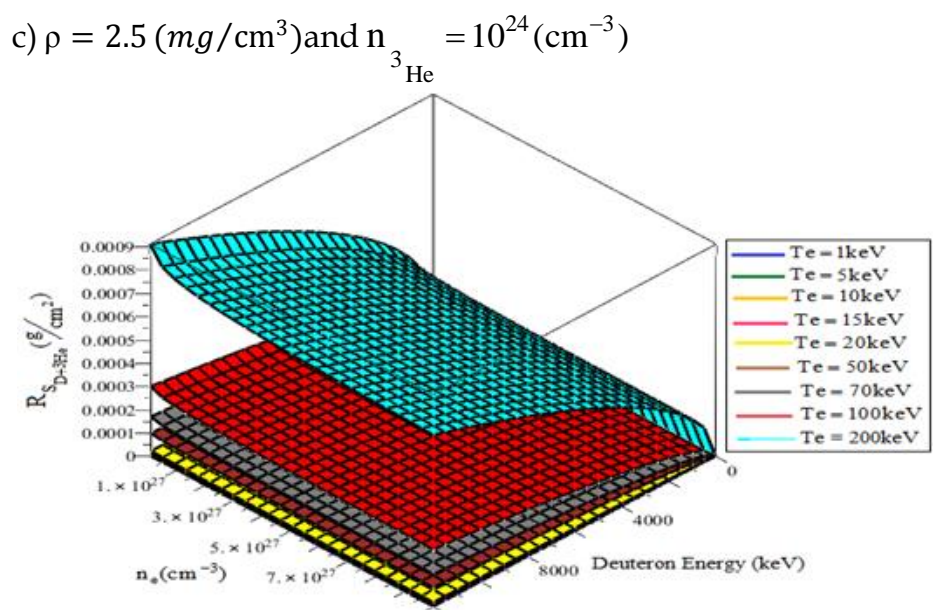

Figure 9: The three dimensional variations of stopping range versus electron density and deuteron energy at different temperatures for three cases a) ,b) and c) in D+ ${ }^{3} \mathrm{He}$ mixture.

\section{BALANCE EQUATIONS OF DEUTERIUM-HELIUM3 MIXTURE}

The following system of equations is used to describe the temporal evolution of plasma parameters averaged over the volume (the density of deuterium ions $n_{D}$, density of helllium-3 ions $n^{3} \mathrm{He}$, density of thermal alpha-particles $n_{\alpha}$, plasma energy $E$ ), for $\mathrm{D}+{ }^{3} \mathrm{He}$ nuclear fusion reaction :

$$
\begin{aligned}
& \frac{d n_{D}}{d t}=-\frac{n_{D}}{\tau_{P}}-n_{D} n{ }^{3} \mathrm{He}\langle\sigma v\rangle_{D+{ }^{3} \mathrm{He}}+S_{D} \\
& (10-1) \\
& \frac{d n{ }^{3} \mathrm{He}}{d t}=-\frac{n{ }^{3} \mathrm{He}}{\tau_{P}}-n_{D} n{ }^{3} \mathrm{He}\langle\sigma v\rangle_{D+{ }^{3} \mathrm{He}}+S_{{ }^{3} \mathrm{He}} \\
& (10-2) \\
& \frac{d n_{\alpha}}{d t}=-\frac{n_{\alpha}}{\tau_{\alpha}}+n_{D} n_{{ }^{3} H e}\langle\sigma v\rangle_{D+}{ }^{3} H e
\end{aligned}
$$

The energy balance is given by

$\frac{d E}{d t}=-\frac{E}{\tau_{E}}+Q_{\alpha} n_{D} n{ }^{3} \mathrm{He}\langle\sigma v\rangle_{D+{ }^{3} \mathrm{He}}-P_{\text {rad }}$

$S_{D}$, and $S_{{ }^{H} \mathrm{He}}$ are the source terms which give us the fuel rates; $\tau_{\alpha^{\prime}}, \tau_{P}$, and $\tau_{E}$ are the lifetimes of thermal alpha-particles, deuterium and hellium-3, and the energy confinement time, respectively, also the energy of the alpha particles is: $Q_{\alpha}=3.52 \mathrm{MeV}=$ $3.6 \times 10^{6} \times 1.6 \times 10^{-19} \mathrm{~J}$.The radiation loss $P_{\text {rad }}$ is given by:

$P_{\text {rad }}=P_{\text {brem }}=A_{b} Z_{\text {eff }} n_{e}^{2} \sqrt{T}$

where $A_{b}=5.35 \times 10^{-37} \frac{\mathrm{Wm}^{3}}{\sqrt{\mathrm{keV}}}$ is the bremsstrahlung radiation coefficients. No explicit evolution equation is provided for the electron density $n_{e}$ since we can obtain it from the neutrality condition $n_{e}=n_{D}+n_{{ }_{3} \mathrm{He}}+2 n_{\alpha}$, whereas the effective atomic number, the total density and the energy are written as:

$Z_{\text {eff }}=\frac{\sum_{i} n_{i} Z_{i}^{2}}{n_{e}}=\frac{n_{D}+n{ }^{3} \mathrm{He}+4 n_{\alpha}}{n_{e}}$ 
where,$Z_{i}$ is the atomic number of the different ions. The fusion energy gain is defined as $: G(t)=\frac{E_{f}(t)}{E_{\text {driver }}}$, where $E_{f}(t)$ is equal to the energy due to the number of occurred fusion reactions in target in terms of time and $E_{\text {driver }}$ is the required energy for triggering fusion reactions in hot spot and is equal to $4 \mathrm{MJ}$ [24]. Also the fusion power density for D+3Hereaction

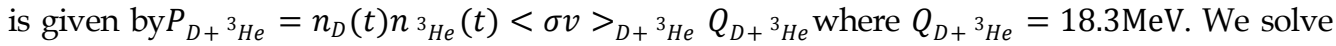
equations (10-1) , (10-2) , (10-3) and (10-4) in dynamical state (time-dependent density of atoms) with the use of computers (programming, Maple-15) under available physical conditions .Our computational obtained results are given in Figs.10 to 12.From Figs.10 to 12 we see clearly that ,by increasing temperature from $1 \mathrm{keV}$ to $200 \mathrm{keV}$ the variations of deuterium and helium-3 density in terms of time $\left(n_{D}(t), n_{{ }_{3} \mathrm{He}}(t)\right)$ are decreased since by increasing time the consumption rate of $n_{D}(t)$ and $n^{{ }^{3} \mathrm{He}}(t)$ are increased.But the changes of $n_{D}(t)$ and $n_{3}{ }_{\mathrm{He}}(t)$,in all temperature are similar and as we see in Figs.10 to 12 they coincide each other. لطفا جى شودThus, by increasing temperature $1 \mathrm{keV}$ to $200 \mathrm{keV}$ the variations of alpha density $\left(n_{\alpha}(t)\right)$ versus time at first by increasing time is increased and then decreased while the production rate of fusion plasma energy $\left(E_{f}(t)\right)$ increases and is maximized at resonant temperature of $200 \mathrm{keV}$, because at this temperature the highest number of $\mathrm{D}+{ }^{3} \mathrm{He}$ fusion reaction occurs. The numerical values of these quantities $\left(n_{\alpha}(t)\right.$ and $\left.E_{f}(t)\right)$ are decreased at temperature higher than $200 \mathrm{keV}$ since temperature $200 \mathrm{keV}$ is resonant temperature for $\mathrm{D}+{ }^{3} \mathrm{He}$ mixture .Also, our calculations show that by increasing the injection rate of deuterium and helium-3 $\left(S_{D}\right.$ and $\left.S_{{ }^{3} \mathrm{He}}\right)$ from $10^{22}$ to $10^{24} \mathrm{~cm}^{-3}$ the rate of variations of $n_{D}(t)$ and $n^{3} \mathrm{He}(t)$ in terms of time are increased while $n_{\alpha}(t)$ and $E_{f}(t)$ increase. We expect that at this temperature, energy gain and fusion power density are maximized. Therefore, for the calculation of theseparameters we use of $S_{D}=S_{3}{ }_{\mathrm{He}}=10^{24} \mathrm{~cm}^{-3}$ (see Table.3).
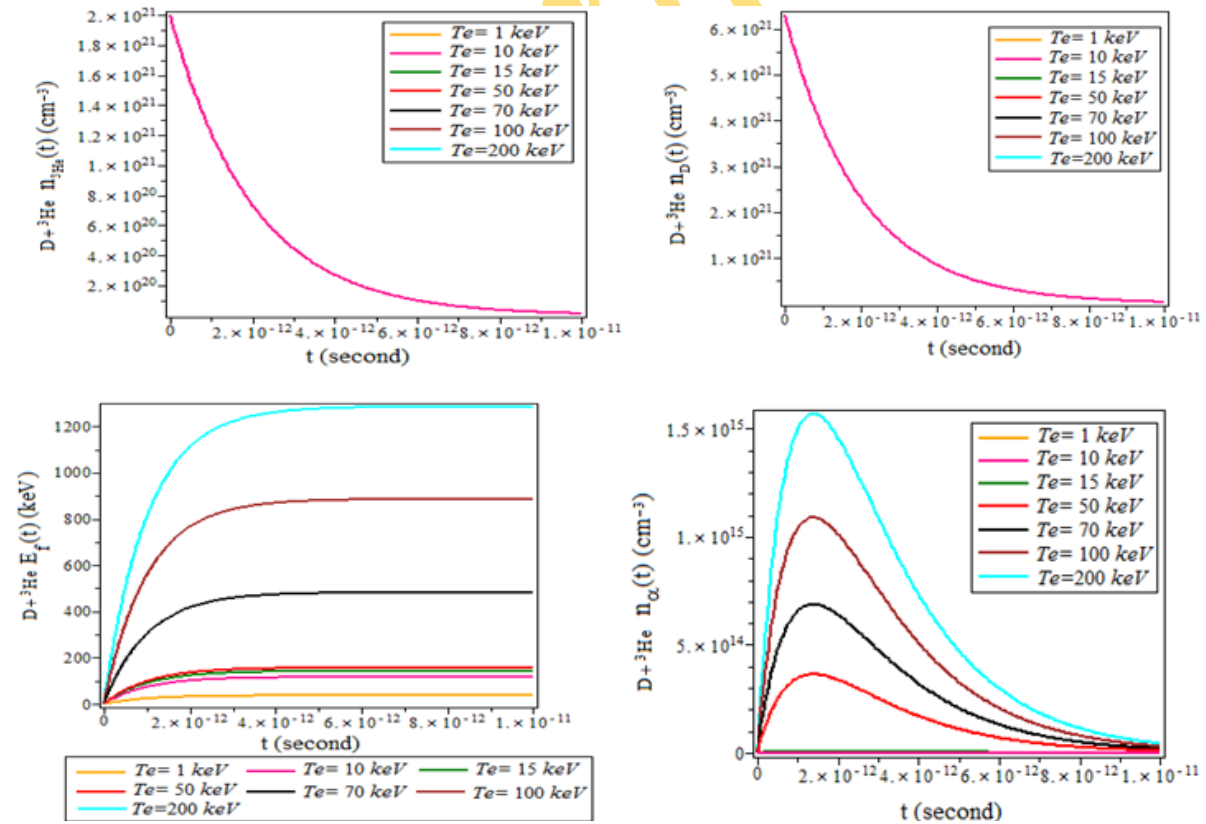

Figure 10: The two dimensional variations of deuterium, helium-3 and alpha particles densities and plasma energy in terms of time at different temperatures for $\mathrm{D}+3 \mathrm{He}$ mixture under choosing $\mathrm{S}^{3} \mathrm{He}=0.20 \times 10^{22}\left(\mathrm{~cm}^{-3}\right)$ and $\mathrm{S}_{\mathrm{D}}=0.63 \times 10^{22}\left(\mathrm{~cm}^{-3}\right)$. 
Asia Pacific Journal of Energy and Environment, Volume 1, No 2 (2014)
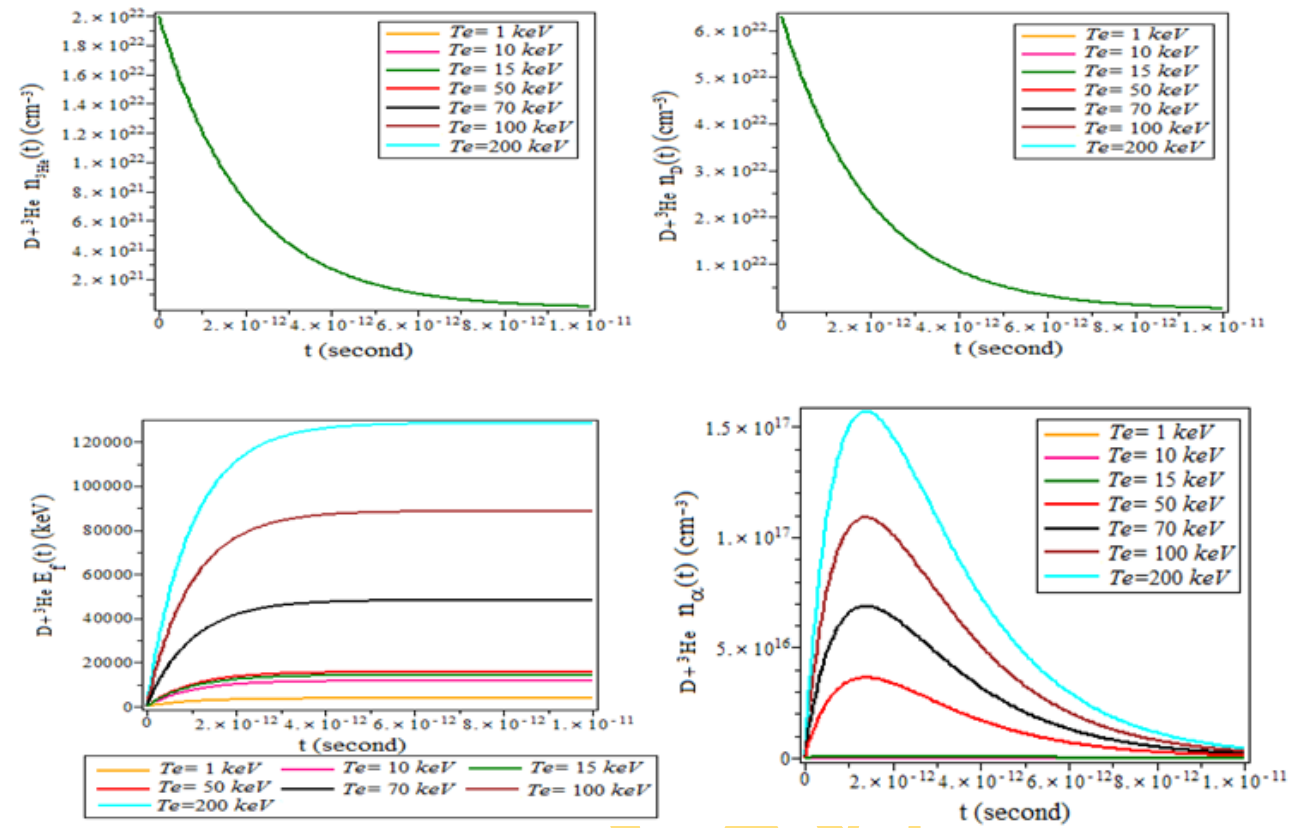

Figure 11: The two dimensional variations of deuterium, helium-3 and alpha particles densities and plasma energy in terms of time at different temperatures for $\mathrm{D}+{ }^{3} \mathrm{He}$ mixture under choosing $\mathrm{S}_{{ }^{3} \mathrm{He}}=0.20 \times 10^{23}\left(\mathrm{~cm}^{-3}\right)$ and $\mathrm{S}_{\mathrm{D}}=0.63 \times 10^{23}\left(\mathrm{~cm}^{-3}\right)$.
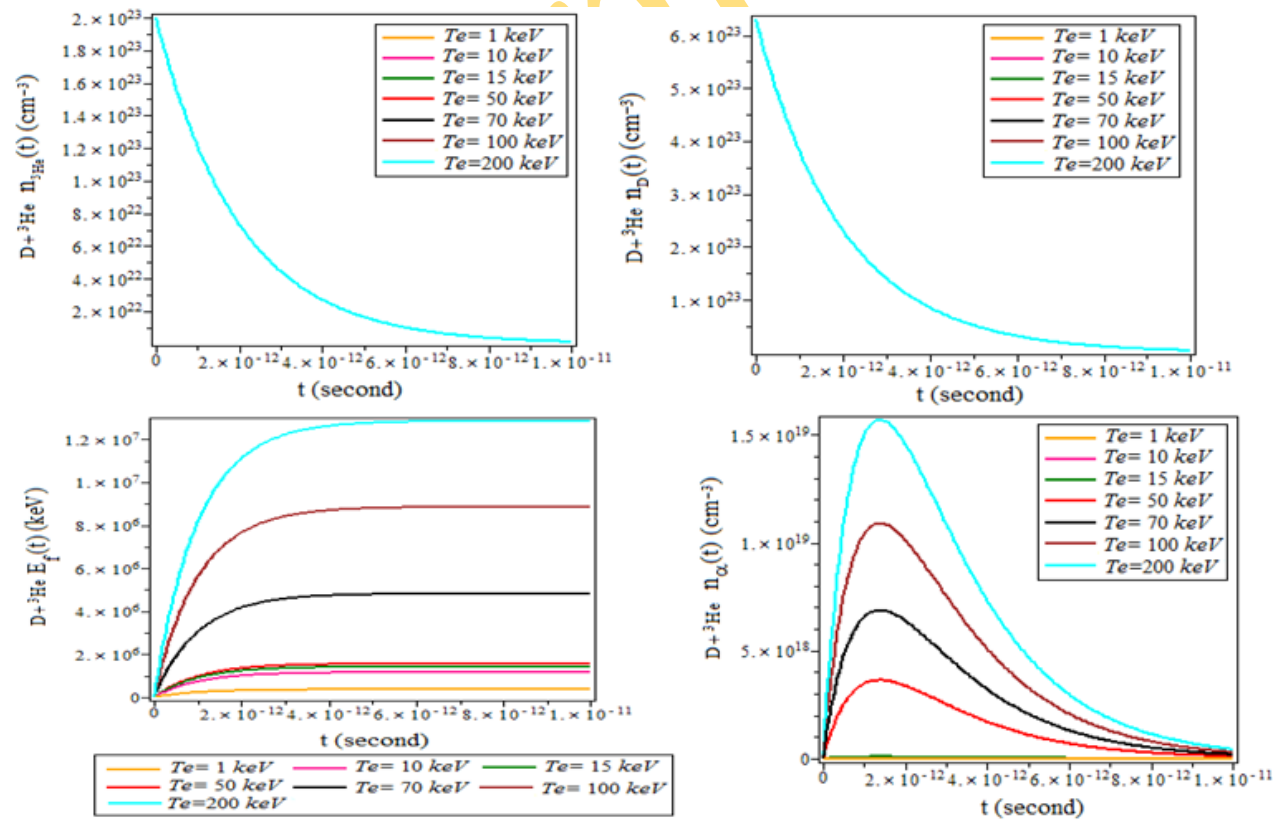

Figure 12: The two dimensional variations of deuterium, helium-3 and alpha particles densities and plasma energy in terms of time at different temperatures for $\mathrm{D}+{ }^{3} \mathrm{He}$ mixture under choosing $\quad \mathrm{S}_{{ }^{3} \mathrm{He}}=0.20 \times 10^{24}\left(\mathrm{~cm}^{-3}\right)$ and $\mathrm{S}_{\mathrm{D}}=0.63 \times 10^{24}\left(\mathrm{~cm}^{-3}\right)$. 
Asia Pacific Journal of Energy and Environment, Volume 1, No 2 (2014)

Table.2: Maximum numerical values of total energy deposited in $\mathrm{D}+{ }^{3} \mathrm{He}$ mixture at different temperature for $10^{26} \leq n_{e}\left(\mathrm{~cm}^{-3}\right) \leq 10^{28}$.

\begin{tabular}{|c|c|c|c|c|c|}
\hline \multicolumn{7}{|c|}{$\mathrm{D}+{ }^{3} \mathrm{He}$} \\
\hline$n_{e}\left(\mathrm{~cm}^{-3}\right)$ & $\mathrm{T}_{\mathrm{e}}(\mathrm{keV})$ & $\varepsilon_{\mathrm{D}+{ }^{3} \mathrm{He}_{\max }}(\mathrm{keV})$ & $\varepsilon_{\mathrm{D}+\mathrm{D}_{\max }}(\mathrm{keV})$ & $\varphi_{\mathrm{D}+{ }^{3} \mathrm{He}_{\max }}$ & $\varphi_{\mathrm{D}+\mathrm{D}_{\max }}$ \\
\hline $10^{26}$ & 15 & 10047.58856 & 10149.90397 & 0.0047588563 & 0.0149903974 \\
\hline $10^{26}$ & 50 & 10840.82266 & 12648.59138 & 0.0840822661 & 0.2648591382 \\
\hline $10^{26}$ & 100 & 12466.83449 & 17770.52865 & 0.2466834492 & 0.7770528649 \\
\hline $10^{26}$ & 200 & 17770.52865 & 22778.7444 & 0.4056744253 & 1.27787444 \\
\hline $10^{27}$ & 15 & 10043.55314 & 10137.19238 & 0.0043553138 & 0.0137192384 \\
\hline $10^{27}$ & 50 & 10762.58435 & 12402.14071 & 0.0762584353 & 0.2402140712 \\
\hline $10^{27}$ & 100 & 12223.67403 & 17004.5732 & 0.2223674032 & 0.7004573201 \\
\hline $10^{27}$ & 200 & 17004.5732 & 21439.64967 & 0.3631634817 & 1.143964967 \\
\hline $10^{28}$ & 15 & 10040.14861 & 10126.46811 & 0.0040148607 & 0.0126468114 \\
\hline $10^{28}$ & 50 & 10697.66667 & 12197.65001 & 0.0697666669 & 0.2197650008 \\
\hline $10^{28}$ & 100 & 12024.14982 & 16376.07194 & 0.2024149822 & 0.637607194 \\
\hline $10^{28}$ & 200 & 16376.07194 & 20354.58457 & 0.3287169706 & 1.035458457 \\
\hline
\end{tabular}

Table.3: Time dependent numerical values of fusion power density and target energy gain.

\begin{tabular}{|c|c|c|c|}
\hline \multicolumn{4}{|c|}{$\mathrm{S}_{\mathrm{D}}=0.63 \times 10^{24}\left(\mathrm{~cm}^{-3}\right), \mathrm{S}_{{ }^{\mathrm{He}}}^{\mathrm{D}+3 \mathrm{He}}=0.20 \times 10^{24}\left(\mathrm{~cm}^{-3}\right)$} \\
\hline $\mathrm{T}_{\mathrm{e}}(\mathrm{keV})$ & $\mathrm{t}(\mathrm{s})$ & $P_{D+{ }^{3} \mathrm{He}}(t)\left(\frac{W}{\mathrm{~cm}^{3}}\right)$ & $G_{D+{ }^{3} \mathrm{He}}(t)$ \\
\hline 15 & $10^{-20}$ & $450.12 \mathrm{E} 15$ & $0.0057096 \mathrm{E}-22$ \\
\hline 15 & $10^{-11}$ & 204.35E11 & $0.57096 \mathrm{E}-16$ \\
\hline 15 & 60 & $180.05 \mathrm{E}-8$ & $2.7702 \mathrm{E}-8$ \\
\hline 15 & 110 & 180.05E-8 & $0.047945 \mathrm{E} 1$ \\
\hline 50 & $10^{-20}$ & 2127.69E16 & $0.0062723 \mathrm{E}-22$ \\
\hline 50 & $10^{-11}$ & 965.87E12 & $0.62713 \mathrm{E}-16$ \\
\hline 50 & 60 & 851.07E-7 & $3.0428 \mathrm{E}-8$ \\
\hline 50 & 110 & 851.07E-7 & $0.052664 \mathrm{E} 1$ \\
\hline 100 & $10^{-20}$ & $639.25 \mathrm{E} 17$ & $0.035428 \mathrm{E}-22$ \\
\hline 100 & $10^{-11}$ & 290.13E13 & 3.5422E-16 \\
\hline 100 & 60 & $255.73 \mathrm{E}-6$ & $1.7186 \mathrm{E}-7$ \\
\hline 100 & 110 & 255.73E-6 & $0.29745 \mathrm{E} 1$ \\
\hline 200 & $10^{-20}$ & 920.77E17 & $0.051412 \mathrm{E}-22$ \\
\hline 200 & $10^{-11}$ & $417.87 \mathrm{E} 13$ & $0.51397 \mathrm{E}-15$ \\
\hline 200 & 60 & 368.31E-6 & $2.4982 \mathrm{E}-7$ \\
\hline 200 & 110 & 368.31E-6 & $0.47692 \mathrm{E} 1$ \\
\hline
\end{tabular}

\section{Conclusion}

The advantages of $\mathrm{D}+{ }^{3} \mathrm{He}$ over $\mathrm{D}+\mathrm{T}$ appear as full-lifetime materials, reduced radiation damage ,less activation , absence of tritium breeding blankets ,highly efficient direct energy conversion ,easier maintenance, proliferation resistance $. \mathrm{D}+{ }^{3} \mathrm{He}$ reaction is very attractive from a theoretical point of view since it does not produced neutrons. A D+3 He fueled fusion reactor would also possess substantial safety and environmental advantages over $\mathrm{D}+\mathrm{T}$. Efficient $\mathrm{D}+{ }^{3} \mathrm{He}$ fusion energy would benefit terrestrial electricity , space power, and 
space propulsion. Fusion using $\mathrm{D}+{ }^{3} \mathrm{He}$ fuel requires significant physics developments particularly for plasma confinement in high performance alternate fusion concept. Economically accessible ${ }^{3} \mathrm{He}$ on earth exists in sufficient quantities (a few hundred $\mathrm{kg}$ ,equivalent to few thousand MW-years of fusion power ) for an engineering test. In a $\mathrm{D}+{ }^{3} \mathrm{He}$ fuel mixture $\mathrm{D}+\mathrm{D}$ reaction fusion also occursThe main difficulties for $\mathrm{D}+{ }^{3} \mathrm{He}$ reaction are the high temperature conditions and the scarceness of ${ }^{3} \mathrm{He}$ on earth. Therefore,from the abovediscussion we select the $\mathrm{D}+{ }^{3} \mathrm{He}$ mixture and estimate dynamically energy gain by calculating the deuteron beam energy deposited in the fuel target. The deposited energy can reduce laser driver energy. Our calculations show that at $200 \mathrm{keV}$ (resonant temperature) the maximum number of fusion reactions are obtained. and the energy gain is maximized. The maximum calculated energy gain under optimum conditions $\mathrm{S}_{\mathrm{D}}=0.63 \times 10^{24}\left(\mathrm{~cm}^{-3}\right), \mathrm{S}_{{ }_{3} \mathrm{He}}=0.20 \times 10^{24}\left(\mathrm{~cm}^{-3}\right)$ and resonant temperature 200keVand $\mathrm{t}=110 \mathrm{~s}$ is approximately equal to 4.77 .

\section{REFERENCES}

A. Caruso and V. A. Pais, Nucl. Fusion 36, 745 (1996);Phys. Lett. A 243, 319 (1998). [6]

A. Maksimchuk, S. Gu, K. Flippo, D. Umstadter, and V. Y. Bychenkov,Phys. Rev. Lett. 84, 4108 (2000). [16]

A. Maksimchuk, S. Gu, K. Flippo, et al., Phys. Rev. Lett. 84, 4108 (2000). [9]

C. Bathke, H. Towner, and G. H. Miley, Trans. Am. Nucl. Soc. 17,41 (1973). [18]

C.Li and R.D.Petrasso,Phys.Plasmas.Vol.2,No.6,2460 (1995). [25]

D. J. Rose and M. Clark, Jr., Plasmas and Controlled Fusion MIT Press, Cambridge, MA, (1965). [21]

D.Baie-Quan ,Y.gian-Cheng,D.Mei-Gen,P.Li-Lin,Chin. Phys.Lett.Vol.19,No.7,962 (2002). [23]

E. L. Clark, K. Krushelnick, J. R. Davies, et al., Phys. Rev. Lett. 84, 670 (2000). [7]

G. H. Miley, Fusion Energy Conversion American Nuclear Society,Hinsdale, IL, (1976). [22]

H. Schwoerer, S. Pfotenhauer, O. Jackel, K. U. Amthor, Ziegler, R. Sauerbrey, K. W. D. Ledingham, and T. Esirkepov, Nature London439,445 (2006) [17]

J D LindlPhys Plasmas 23933 (1995) and Phys Plasmas 11339 (2004) [1]

J. R. Rygg, J. A. Frenje, C. K. Li, F. H. Séguin, R. D. Petrasso,J. A. Delettrez, V. Yu. Glebov, V. N. Goncharov, D. D. Meyerhofer,P. B. Radha, S. P. Regan, and T. C. Sangster,PHYSICS OF PLASMAS14,056306(2007). [27]

J.P.Freidberg, "Plasma Physics and Fusion Energy", Cambridge University Press ,New York (2007). [26]

K. A. Tanaka, R. Kodama, H. Fujita, et al., Phys. Plas-mas 7, 2014 (2000). [5]

M Tabak et al Phys Plasmas 11626 (1994) [4]

M TEMPORAL J Honrubia, S Atzeni. Phys. Plas.9,3102,(2002) [15]

M. L. Shmatov, J. Br. Interplanet. Soc. 57,362(2004). [19]

M. L. Shmatov, J. Br. Interplanet. Soc. 60,180 (2007). [14]

N. Naumova, T. Schlegel, V. T. Tikhonchuk, C. Labaune, I. V. Sokolov,and G. Mourou, Phys. Rev. Lett. 102, 025002 (2009). [12]

N.G. Basov, S.Y. Guskov and L.P. Feokistov, J. Sov. Laser Res. 13, 396 (1992). [3]

S .Pfalzner, "An Introduction to Inertial Confinement Fusion", Published by CRC Press Taylor \& Francis Group (2006). [24]

S E Bodner et al. Phys Plasmas 5, 1901 (1998) [2]

S. P. Hatchett, C. G. Brown, T. E. Cowan, et al., Phys. Plasmas 7, 2076 (2000). [8]

V. Bychenkov, W. Rozmus, A. Maksimchuk, D. Umstadter, and C.Capjack, Plasma Phys. Rep. 27, 1017 (2001). [11]

V. T. Tikhonchuk, T. Schlegel, C. Regan, M. Temporal, J.-L. Feugeas, P.Nicolaï, and X. Ribeyre, Nucl. Fusion 50, 045003 (2010). [13]

XiaolingYang,George H. Miley,Kirk A. Flippo, and Heinrich Hora, PHYSICS OF PLASMAS 18, 032703 (2011) [20]

Xing Z. Li, Qing M. Wei and Bin Liu, Nucl. Fusion 48 ,125003 (5pp) (2008). [10] 


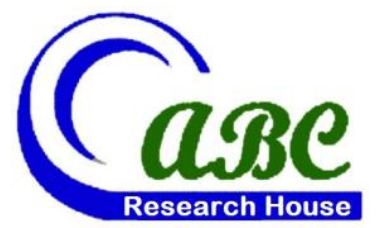

- Rd 4, Shyamoli, Dhaka-1207, Bangladesh

- Off Pantai Dalam, Kuala Lampur, Malaysia

- 3900 Woodhue Place, Alexandria, VA 22309, USA

www.abcreorg.weebly.com / www.abcjournals.net

Asian Business Consortium (ABC) is a multi-disciplinary research, training, publishing, digital library supporting and service house. Though founded in 2010 as the Business and Computing organization of Asia, it was reconstituted as the ABC in 2011. It has been working for creating and nurturing talents in USA, Malaysia and Bangladesh since its inception. As ABC is going global, it intends to open chapters in Australia, Germany, Japan, Pakistan, and other Asian countries in near future. The objectives of consortium are solely centered round the welfare and humane attitude of the founders who enthusiastically took up this noble cause and materialized it with a view to promote research and educational activities for the encouragement of scholars to develop their knowledge, to publish their analysis oriented scientific researches in international Journals, books, the task of organizing workshops, seminars, conferences, training, personality development programs and allied services.

In addition to research activities, ABC provides a good number of scholarships to the poor and meritorious students at various levels of education throughout the world. It plays an important role in the field of research by funding research projects and publishing the research papers. This consortium will unquestionably become the mouth-piece of the dark horses and unacknowledged scholar whose endowed and commendable contributions shall be provided an outlet keeping in mind the greater good of the larger society of the world.

$\mathrm{ABC}$ runs the following international referred journals for creating a platform to share the thoughts of professionals, scholars and academicians throughout the world.

\section{ABC Publications (ABC Journals)}

- Asian Accounting and Auditing Advancement (4A Journal)

- Asian Business Review (ABR)

- Asian Journal of Applied Sciences and Engineering (AJASE)

- Global Disclosure of Economics and Business (GDEB)

- $\quad$ ABC Journal of Advanced Research (ABC-JAR)

- International Journal of Reciprocal Symmetry and Theoretical Physics (IJRSTP)

- American Journal of Trade and Policy (AJTP)

- Asian Journal of Humanity, Art and Literature (AJHAL)

- Malaysian Journal of Medical and Biological Research (MJMBR)

- Asia Pacific Journal of Energy and Environment (APJEE)

- $\quad$ Engineering International (EI)

- $\quad$ ABC Research Alert (Online)

Each journal home page provides specific information for potential authors and subscribers. Open access policy, the quick review process, rich editorial boards and quality publications have already made $A B C$ Journals unique. ABC Journals are published under the direct supervisions of renowned academicians of the world.

Collaboration in Conference: $\mathrm{ABC}$ considers high-quality conference papers for publication. Please contact us for detailed information.

Collaboration in Publishing: If you like to start writing a book, propose a new journal or advertise in $\mathrm{ABC}$ journals, please feel free to contact us. 